Article

\title{
Investigating the Climate-Induced Livelihood Vulnerability Index in Coastal Areas of Bangladesh
}

\author{
Mehedi Mudasser ${ }^{1}$, Md. Zakir Hossain ${ }^{2}\left(\mathbb{D}\right.$, Khan Rubayet Rahaman ${ }^{3, *(1)}$ and \\ Nur Mohammad Ha-Mim ${ }^{2}$ D \\ 1 National Resilience Programme (NRP), UNDP Bangladesh, IDB Bhaban, 18th Floor, UN Offices, E/8-A, \\ Begum Rokeya Sarani, Dhaka 1207, Bangladesh; mehedi.mudasser@undp.org \\ 2 Urban and Rural Planning Discipline, Khulna University, Khulna 9208, Bangladesh; \\ zakir@ku.ac.bd (M.Z.H.); nurhamimurp15@gmail.com (N.M.H.-M.) \\ 3 Department of Geography and Environmental Studies, St. Mary's University, 923 Robie Street, Halifax, \\ NS B3H 3C3, Canada \\ * Correspondence: khan.rahaman@smu.ca
}

Received: 31 July 2020; Accepted: 10 September 2020; Published: 15 September 2020

check for updates

\begin{abstract}
Understanding the complex dynamics of a household's livelihood and potential vulnerabilities in the face of climate change is challenging. This research paper considers the Shyamnagar sub-district in the southern part of Bangladesh to analyze the complex issues of the vulnerability of livelihoods in the face of climate change. We conducted a questionnaire survey ( $n=156)$ of approximately $15.6 \%$ of households in the study area. Consequently, we collected Geographical Information System (GIS) data and satellite imagery to demonstrate the land-use changes concerning vulnerabilities. A total of 54 indicators were selected to assess the livelihood vulnerability index, considering the demographic profiles, livelihood strategies, social networks, food security, water security, income, physical infrastructures, access to health services, and impacts of natural disasters. The results of the study demonstrate that only $21 \%$ of the people in the studied regions are less vulnerable to livelihood impacts in the face of climate change, while $23 \%$ of the households remain the most vulnerable. Moreover, inadequate social networks and inefficient livelihood strategies are contributing the most to the household vulnerability indices. Interestingly, the impacts of natural disasters remain the same for the whole study area and endure similarly when assessing household vulnerability. Finally, the study reveals that decision-makers may formulate effective adaptation policies to safeguard people and their livelihoods in the time of unprecedented climatic conditions in this unique area of Bangladesh.
\end{abstract}

Keywords: climate change; adaptation; planning; households; local area

\section{Introduction}

This research intends to understand the extent of climate-induced stresses (i.e., household-level vulnerabilities) of people in the coastal rural settlements in Bangladesh. Climate change and its associated impacts are already being embraced through changing temperatures and precipitation, rising sea levels, changes in the frequency and severity of climate extremes, and the dynamics of hazardous conditions [1]. In the past ten years, global scientific assessment reports have concluded that climate change is already occurring, partly driven by anthropogenic interference with the climate system, and that important impacts are unavoidable over the coming decades [2]. Moreover, these climate change impacts will disproportionately affect the developing or least-developed countries of the world, whose populations are collectively both the least responsible for contributing to rising emissions levels and the least able to deal with the associated consequences [3,4]. In most developing countries, 
poor populations commonly live in vulnerable locations-more geographically exposed and marginal regions-and their livelihoods depend on natural resources that are more sensitive to changes and variability in climate and extreme weather events. At the same time, they possess limited resources to mobilize coping strategies in order to introduce longer-term adaptation mechanisms [5]. In order to support these poor populations to build adaptations to climate change and climate extremes, vulnerability assessments have become necessary for exploring sensitive and influential factors.

Several comprehensive and varied conceptual frameworks regarding vulnerability assessment techniques exist in contemporary literature. Scholars of different disciplines conceptualized vulnerability in a variety of ways, and considered a series of approaches in mapping and theorizing the components of vulnerability over the years [6,7]. The Romans historically used the term "vulnerability" to state the condition of injured soldiers who had a risk of future attack [8]. Again, Adger [9] highlighted vulnerability as the impact of negative social and environmental change that disrupted the livelihoods of individuals or groups of people, and also defined "social vulnerability" based on the exposure of the social groups to any external shocks. On the other side, focusing on famine and food insecurity, scholars have defined vulnerability as the failure of production, leading to food shortages, which resulted in the corrosion of entitlements and capabilities [10,11]. According to one school of thought [12,13], vulnerability was considered as exposure to hazards, focusing on identification of vulnerable groups, whereas others [14-17] focused on identification of the root cause. Furthermore, vulnerability could be linked to disaster management and the political economy [18]. While conceptualizing vulnerability to climate change, the Intergovernmental Panel on Climate Change (IPCC) incorporated three core concepts: exposure, sensitivity, and adaptive capacity [19]. Therefore, it was noted that vulnerability to climate change had three parts: risk as climate change, climate variability, and extremes; response as determined by sensitivity and adaptive capacity; and outcome as potential impacts. Most vulnerable individuals, households, groups, and classes would be those that (a) are most exposed to shocks and stresses due to climate change, including climate variability and extremes; (b) are most sensitive to climatic shocks and stresses; and (c) have the least capacity to respond. Most of the literature used these core concepts of vulnerability, such as exposure, sensitivity, and adaptive capacity, when assessing vulnerability to climate change [20-23].

In the context of vulnerability assessment, scholars have adopted diverse assessment approaches and applied them at different scales. Upon reviewing the relevant literature, climate change assessments have been categorized in diverse groups, such as the "Livelihood Vulnerability Index" in the context of climate change [19,22-25], "Social Vulnerability to Climate Change" [3,26,27], "Climate Vulnerability Index" [20,28,29], and "Household Vulnerability to Climate Change" [21,30-32]. Of the vulnerability indices, the "Livelihood Vulnerability Index" has been most cited, notably considering a wide range of parameters [19,22-25]. For example, scholars [21] have used the three core concepts of exposure, sensitivity, and adaptive capacity. Interestingly, for the vulnerability indicators, scientists have used demographics, socially vulnerable groups, land, physical infrastructure, economic capability, human capital, and institutional capital. However, few scientists [30] have utilized the term "Sustainable Livelihood Framework (SLF)" in order to measure household vulnerability considering the five assets of the social, human, financial, natural and physical, and livelihood diversification aspects. The vulnerability indices found in the scholarly literature [19-32] reveal combined and individual scores of various dimensions of vulnerability at different spatial settings, which range from small communities to regions. The findings from the aforementioned vulnerability indices have contributed to developing effective adaptations for communities and regions, but vulnerable households may be left out of the adaptation planning processes. All the above-mentioned indices have literally failed to identify the extent of individual households' climate sensitivity. In addition, they do not consider resource allocations at the individual level for enhancing the adaptation of each household.

Hence, this study is designed to explore households' vulnerability in relation to climate-induced stresses. Therefore, the research questions are summarized as follows: (i) Are communities vulnerable to climate-induced risks with respect to livelihood? (ii) What are the major factors of stress for 
households' vulnerability in southwestern coastal Bangladesh? (iii) How are the outliers being characterized to respond to policy frameworks? This research introduces the three core concepts of exposure, sensitivity, and adaptive capacity. These concepts help in identifying the appropriate indicators for measuring a household's livelihood vulnerability summary. According to this framework, a household's risk exposure and sensitivity depend on its asset portfolio and livelihood strategies. The capacity of a household to address a wide range of direct and indirect risks associated with climate change has been shaped by policy, social networks, and local institutional systems. It relies on the statistical behavior of environmental, physical, socio-economic, and political variables, for which the weighting and aggregation mechanism of the composite vulnerability indicator is similar to prior scholarly literature $[19,22,23]$. The composite livelihood vulnerability score demonstrates a potentially vulnerable state of the households. This information provides a procedure of relative comparison among communities that are affected by climate-induced risks at the community level. Additionally, the outcome may be useful for setting up future adaptation strategies at the household level to avert climate-induced risks in the global south.

\section{Materials and Methods}

\subsection{Study Area}

We have selected Shyamnagar Upazila (sub-district level of the administrative boundary of the country) of Satkhira District in Bangladesh as our study area. Shyamnagar occupies an area of 1968.24 sq. km, including 1534.88 sq. km of forested area [33]. In the south, it is surrounded by the Sundarbans (i.e., one of the most extensive mangrove forests in the world), while in the west, the area is demarcated by the Hariabhanga River that forms the border with West Bengal in India (see Figure 1 for details). Kaliganj and Assasuni Upazila are located on the western side of Shyamnagar Upazila. In the east, the area is surrounded by Koyra Upazila of the Khulna district. It is situated between $21^{\circ} 32^{\prime}$ and $22^{\circ} 24^{\prime}$ north latitude and $89^{\circ} 00^{\prime}$ and $89^{\circ} 20^{\prime}$ east longitude. We have considered Shyamnagar Upazila as the study area because it is one of the most disaster-affected sub-districts in the south-western coastal region of the country. Moreover, the poverty level is comparatively higher in this sub-district (as shown in the Bangladesh lower poverty map of 2010, the percentage of the population live in extreme poverty is $35 \%$ or greater) [34]. The area was severely affected by cyclone Aila in May 2009, just two years after the devastating cyclone Sidr in 2007. While the people of this sub-district are struggling for the recovery of cyclone-hit damages, another outrageous cyclone, Aila, has struck this south-western coastal area [35]. The damages caused by cyclone Aila were worse as the water stayed for an exceptionally long duration, which has caused an increase in water salinity [36]. The people's livelihoods in Upazila have been completely changed and became challenging because they are living with risks from cyclones and floods, waterlogged soils, increasing salinity of both land and water, and frequent droughts [37].

In this study, we have considered four unions (the lowest rural administrative unit in Bangladesh), namely, Buri Gualini, Ishwaripur, Gabura, and Munshiganj, to understand the differences in household-level livelihood vulnerability to climate change and variability (see Figure 1 for details). The population sizes of these four unions are 6044, 6996, 7491, and 7206, respectively [33]. Among the unions, Munshiganj is the largest (49 sq. km.) and Buri Gualini is the smallest (17 sq. km.). The area of the other two Unions, such as Gabura and Ishwaripur is 33 sq. km. and 19 sq. km. respectively.

We have selected these four unions because of its geographical location and changing nature of the area's rural livelihood after cyclone Aila. It is noted that cyclone Aila has had adverse effects on these unions in many ways, such as changing livelihood patterns and increasing mental stress among the residents. We have selected Gabura, here as the union that has mostly gone underwater because of cyclone Aila, and where people's livelihood has been changed a lot since then. Previously, people have mainly engaged in shrimp or crab culture, rice cultivation, fishing, and resource extraction from the nearby Sundarbans Reserve Forest (SRF). However, the villagers are now only engaged 
in shrimp collection, and going to the SRF for fishing or collecting honey. Although Buri Gualini has similar characteristics as Gabura, we have selected Buri Gualini due to its adjacent location to Sundarbans. Munshiganj has also been affected by cyclone Aila, and embraced hazardous conditions (i.e., saline water intrusion), but the level of destruction is relatively lower than the other two unions, Buri Gualini and Gabura. Finally, we have selected Ishwaripur Union as it is located somewhat distant from Sundarbans. The choosing of Ishwaripur Union as a study area will help us to understand the livelihood dependency issues on Sundarbans and if it proves any relationship on the households' coping mechanism. After Aila, the people in this Union still cultivate rice in their land although the agricultural land mostly became waterlogged. Along with agriculture, people also do shrimp farming, but the extent is minimal.

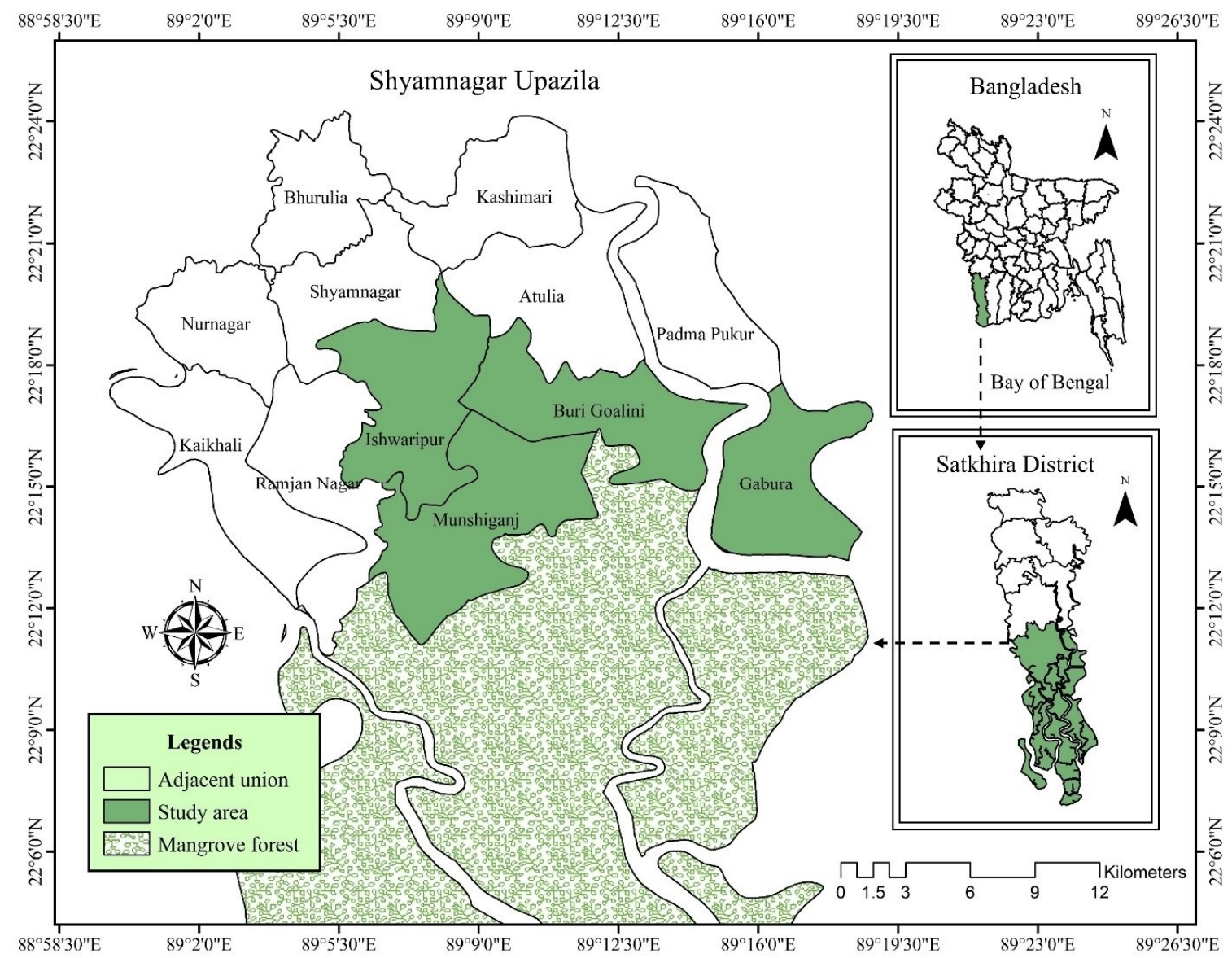

Figure 1. Locational map of the study area.

\subsection{Data Collection and Analysis}

Although this research follows a mixed-method research strategy, we developed this article by the empirical findings obtained from a quantitative research method. We followed several steps for data collection and analysis that are summarized here (see Figure 2) [19,20,23-25,30,37-43]. 


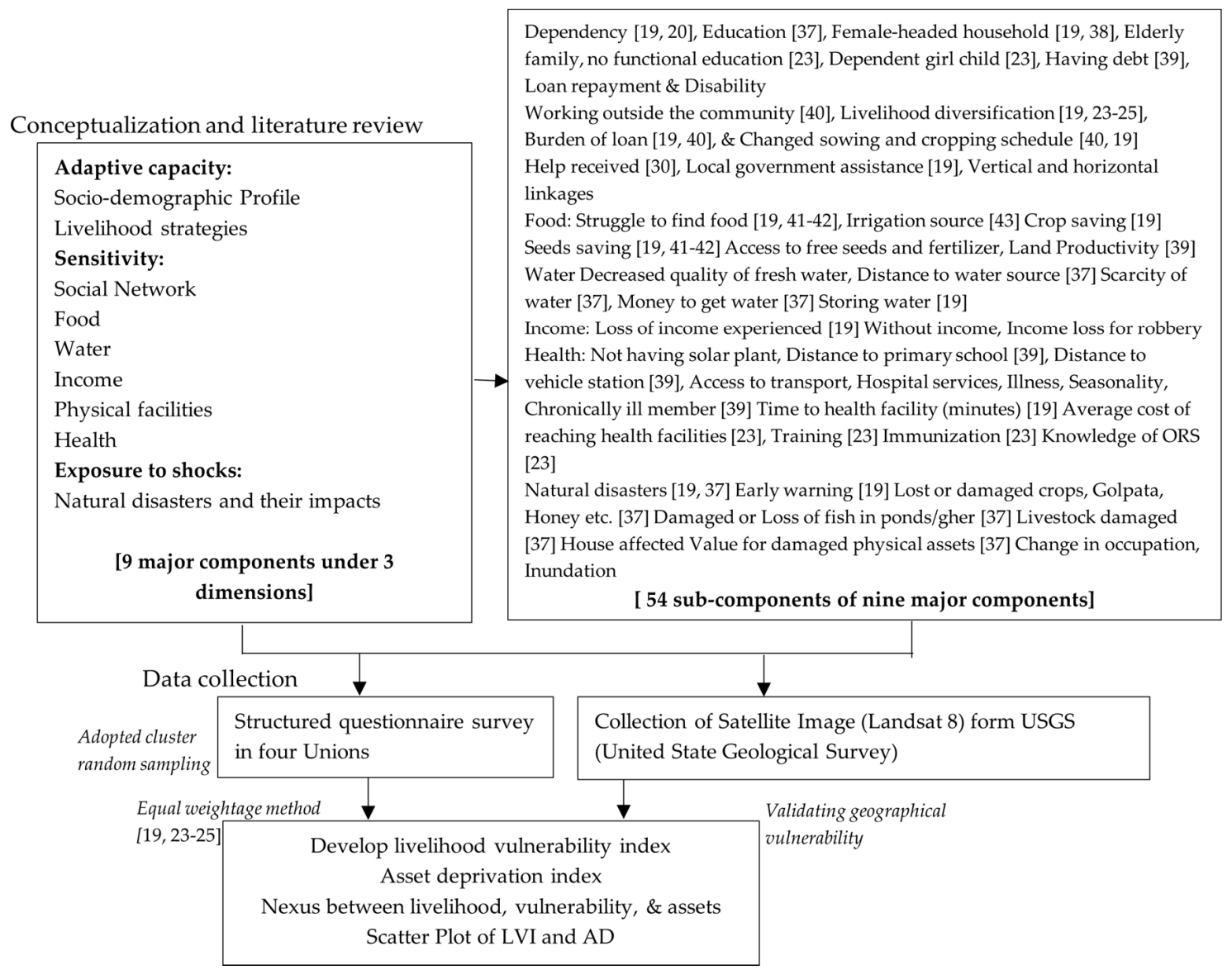

Figure 2. The step-by-step research process followed in this research.

\subsubsection{Structured Questionnaire Survey}

We adopted a structured questionnaire survey method for collecting the household data. We mainly designed the household survey in the form of a close-ended questionnaire, with few open-ended options. The questionnaire was divided into five different sections, highlighting (i) the socio-economic characteristics of the respondents; (ii) perception, knowledge, and attitude related to adaptation; (iii) food security and health status of the households; (iv) household assets and livelihood strategies; and (v) shocks, stresses, and coping strategies for adaptation. We developed the questionnaire in such a way that we could gather more than $60 \%$ of the answers through direct discussion with the family members, observation in reality, and watching the socio-economic conditions of the neighbors. Note that we followed a cluster random sampling technique to conduct the structured questionnaire survey for quantitative information.

\subsubsection{Determination of the Sample Size}

There are twenty-seven thousand seven hundred and thirty-seven $(27,737)$ households that are living within the four unions, namely, Buri Gualini, Gabura, Ishwaripur and Munshiganj of Shyamnagar Upazila. We have used the cluster sampling method to select the samples representing all the studied unions. We selected eight clusters of villages from the four unions (see Figure 3 for details) to distribute the desired samples to conduct the structured questionnaire survey. We have opted to cover most of the areas in our sample. For this, at a $92 \%$ confidence level with a precision of 0.08 , we have considered the following equation to select an appropriate number of households under investigation:

$$
n=\frac{N}{1+N\left(e^{2}\right)}
$$


where $n=$ sample size, $N$ = population size (here a number of households in the sample frame), and $e$ $=$ level of precision/error margin. As the total number of rural households in the sample frame $N$ is 27,737 , and the level of precision/error margin is 0.08 , the obtained sample size is 156 .

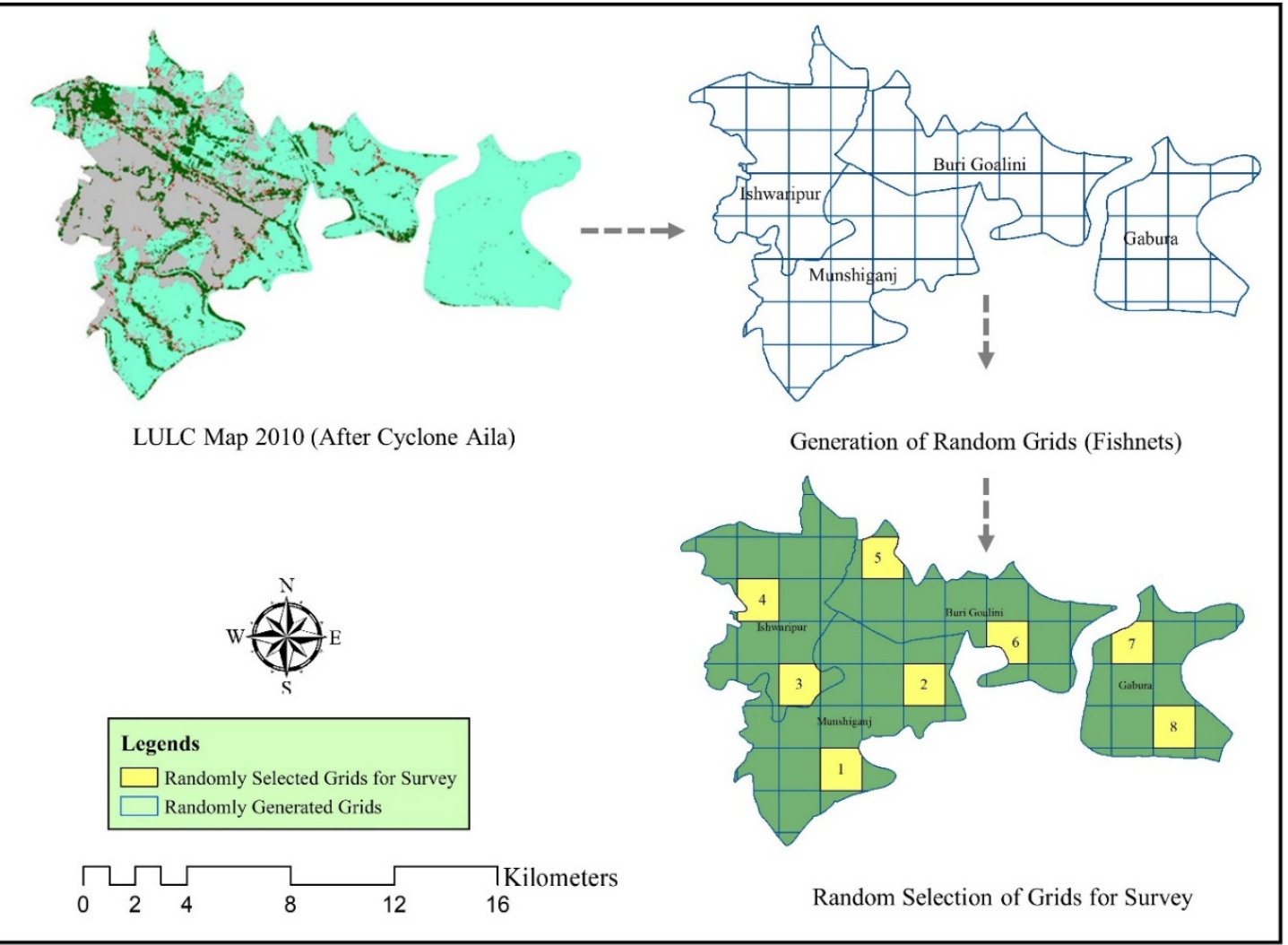

Figure 3. Cluster sampling procedure; $1-8$ are the villages that were selected for conducting the household survey.

We adopted the cluster random sampling procedure for the one hundred and fifty-six sampled households, and eight clusters were selected from the four unions (Buri Gualini, Gabura, Ishwaripur and Munshiganj; see Figure 3). We first explored the most affected areas of cyclone Aila by an analysis of multi-temporal satellite imagery in order to define a cluster. We used Landsat Thematic Mapper (TM) for land use/cover classification where the size of each classified land use/cover helped us to define a cluster. We collected multispectral imagery at both a $30 \mathrm{~m}$ and $15 \mathrm{~m}$ spatial resolution from Landsat $5 \mathrm{TM}(2008,2010)$ for analyzing the land use/cover of the study area using the earth explorer site (http://earthexplorer.usgs.gov/). We extracted the downloaded data and imported it into ERDAS IMAGINE 2014 (Leica Geosystems, Atlanta, GA, USA), which helped us for both geospatial data and other image processing.

We have adopted a hybrid classification method for scrutinizing the land use/cover classification that assisted us to explore the severity of cyclone Aila on it. Upon comparing the land use/cover of 2010 with land use/cover 2008, we defined the affected clusters in the four studied unions. We identified four land use/cover types using a hybrid classification within the unions for the year 2008 that included vegetation, agricultural land, gher (i.e., aquaculture ponds) and water body, as well as built-up area. The image of 2010 was also classified into four classes but not similar to that of 2008; these land-use classes were vegetation, unused agricultural land, gher and water body, as well as built-up area (see Supplementary Table S1). The final maps were exported from ArcGIS 10.3.1 (see Figure 3 for details). Data registered in Table S1 (Supplementary Material) and Figure 3 revealed that positive and negative changes occurred in the land use/cover pattern within the four unions. Immediately after cyclone Aila, the vegetation in the study area decreased from 6619.1427 acres in 2008 to 4527.96207 acres in 2010, 
which accounted for $5.07 \%$ of the total study area. Additionally, gher and water bodies were increased by $7 \%$. The total agriculture land ( $24.7 \%$ of total land use/cover) was converted into unused agriculture land, which was $0 \%$ in 2008 and became $26.41 \%$ of the total land later on. Based on the findings from land use/cover analysis, we defined the most affected to moderately affected areas within four Unions and from moderate to most affected areas. Then we selected eight clusters for collecting the relevant information aligned with our study objectives. The data collection had been performed randomly afterwards. The sample of 156 households was about $15.6 \%$ of the total cluster population, which was nearly 1000 households [33].

\subsubsection{Spatial Data Collection and Analysis}

Spatial data were collected for identifying the geographical vulnerability of the Buri Gualini, Ishwaripur, Gabura, and Munshiganj Unions. Moreover, the data was used to calculate the average distance from the coast, the average distance from the major river, and mean elevation from mean sea level, etc. It incorporated the collection of satellite images (Landsat 8-OLI) from the USGS (United State Geological Survey) for analysis of the DEM (Digital Elevation Model) and land-use classifications to explore inundation scenarios of the study area.

\subsubsection{Construction of the Composite Livelihood Vulnerability Index}

We have estimated households' livelihood vulnerability and climate-induced stresses by developing and applying the livelihood vulnerability index (LVI), which is similar to the "LVI" mechanism developed in previously published scientific research [19,22,23,40-42]. Data driven from the questionnaire surveys were aggregated by using a composite index and differential vulnerabilities index at both the community and household level and then compared. We have included nine major components for generating an LVI: (i) socio-demographic profile (SDP), (ii) livelihood strategies (LS), (iii) social network (SN), (iv) food security (FS), (v) water scarcity (WS), (vi) income (I), (vii) physical facilities (school, transportation, and hospital) (PF), (viii) health services (HS), and (ix) natural disaster and their impact (NDI). Each set is comprised of several indicators or sub-components and a total of 54 indicators were selected (see Supplementary Table S2). These were developed based on a review of the relevant literature on each major component. Table S2 (Supplementary Material) includes an explanation of the quantification process of each indicator and the sources.

We constructed the LVI following a balanced weighted average [19,22,23,40-46], where each sub-component contributed equally to the overall index, although each major component had a different number of sub-components. As fifty-four sub-components were selected, the indicators were equally weighted. Therefore, each of them received a $1 / 54$ weight. The weight of each major component was calculated by multiplying $1 / 54$ with the number of sub-components or indicators within a major component (e.g., weight for the major component socio-demographic profile is $9 \times 1 / 54$ ). Each of the sub-components was measured on a different scale with first standardized as an index using Equation (1). The equation used for this conversion was adapted from the Human Development Index [44] to calculate the life expectancy index. Afterwards, the following equation (Equation (2)) was used in measuring both the LVI [19-30,40-42] and Resilience Index [45].

$$
\text { Index } S_{B_{x}}=\frac{S_{B_{x}}-S_{\min }}{S_{\max }-S_{\min }}
$$

In the index, $S_{B_{x}}$ is the original subcomponent of a household of Buri Gualini and for Gabura, Ishwaripur and Munshiganj. The subcomponents of each household are $S_{G_{x}}, S_{I_{x}}$, and $S_{M_{x}}$, respectively, and $S_{\max }$ and $S_{\min }$ are the minimum and maximum values for each subcomponent. It was determined by using data obtained from Buri Gualini and Gabura of the Shyamnagar Upazila. For example, the "average number of dependent people in a household" subcomponent in the SDP parent component ranged from 0 to 7 , in the four unions we surveyed. These minimum and maximum values were used to transform this indicator into a standardized index so that it could be integrated into the SDP 
component of the LVI. For variables that measured frequencies, such as the "percent of households" heads reporting no primary education", the minimum value was set at 0 and the maximum at 100 . Some sub-components, such as the "average agricultural and non-agricultural livelihood diversification index" was created because an increase in the crude indicator, in this case, the number of agriculture and non-agriculture livelihood activities undertaken by a household, was assumed to decrease vulnerability. In other words, we assumed that a household who engaged in farming and had a rickshaw or a van would become less vulnerable than a household who only farmed. By taking the inverse of the crude indicator, we created a number that assigned higher values to households with a lower number of agricultural and non-agricultural livelihood activities [19,40-42]. The maximum and minimum values were also transformed following this logic [19,40-42]. Subsequently, Equation (2) was used to standardize these sub-components. Once each component was standardized, the subcomponent was averaged using Equation (3) to calculate the value of each major component:

$$
M_{B x}=\frac{\sum_{i=1}^{n} \operatorname{Index}_{B x^{i}}}{n}
$$

where $M_{B x}$ equals one of the major components for a household of Buri Gualini, the Index ${ }_{B x}{ }^{i}$ represents the subcomponents, indexed by $i$, which makes up each major component, and $n$ is the number of subcomponents in each parent component. Once values for each of the major components for a household were calculated, it was averaged using Equation (4) to obtain the LVI at the household level. The LVI is scaled from 0 (least vulnerable) to 1 (most vulnerable). The household-level LVI was calculated as the weighted average of the nine major components.

$$
L V I_{B x}=\frac{\sum_{i=1}^{9} W_{M i} M_{B x}}{\sum_{i=1}^{9} W_{M i}}
$$

which can also be expressed as

$$
L V I_{B x}=\frac{W_{S D P} S D P_{B x}+W_{L S} L S_{B x}+W_{L A} L A_{B x}+W_{F S} F S_{B x}+W_{W S} W S_{B x}+W_{I} I_{B x}+W_{P F} P F_{B x}+W_{H S} H S_{B x}+W_{N D T I} N D T I_{B x}}{W_{S D P}+W_{L S}+W_{L A}+W_{F S}+W_{W S}+W_{I}+W_{P F}+W_{H S}+W_{N D T I}},
$$

where $L V I_{B x}$ is the livelihood vulnerability index for a household of Buri Gualini, and the weight of the major component, $W_{M i}$, was determined by the number of subcomponents that make up each parent component, and contributes equally to the overall LVI [19,40-42]. In this study, the LVI is scaled from 0 (low vulnerable) to 1 (highly vulnerable).

\section{Results}

We present the results in three sections. The first part deals with comparing and contrasting the livelihood vulnerability index of the four unions by using the major components and sub-components. The second part addresses the household-level analysis for identifying the household vulnerability clusters and contributing factors. Finally, we investigated the nexus of the livelihood vulnerability index (LVI) and the asset deprivation index (ADI) to determine the vulnerable categories or clusters concerning asset deprivation.

\subsection{Results: Comparing LVI among the Unions}

Figure 4 represents the LVI score of the major components for each union. Consequently, Table S3 (see Supplementary Materials for details) represents the score of the sub-components of the LVI for each union. The dependency ratio index is the highest for Gabura (0.545788) and the lowest for Ishwaripur (0.454212). It is slightly lower in the other two unions of Munshiganj (0.538462) and Buri Gualini (0.501832). The percentage of household heads having no primary education is the highest in Buri Gualini (74.4\%) and the lowest in Gabura (48.7\%). The level of no formal elementary education among the household heads in the case of the other two unions, Munshiganj (69.2\%) and 
Ishwaripur (66.7\%), is also high. Gabura respondents have reported a higher proportion $(48.7 \%)$ of female-headed households than the other unions, which is relatively higher while comparing with $10 \%$ nationally [47]. Interestingly, the proportion of total female-headed households in the other three unions, Munshiganj (15.4\%), Ishwaripur (12.8\%), and Buri Gualini (28.2\%), is also higher than the national average. After cyclone-Aila, male members in the family have been migrating outside the community in search of new opportunities. Indeed, the agriculture-based work opportunities have become scarce because of waterlogging conditions, and thus male workers have left the areas. Many female members in the households having no formal education have been reported in all the four unions, and the statistics are more than $30 \%$ for each union. The percentage of single-headed elderly households in all four unions is relatively lower in comparison to other the sub-components' values. The disability index score is comparatively lower in the unions as the same percentage of disability $(28.2 \%)$ is present in the three unions of Munshiganj, Ishwaripur, and Buri Gualini. The respondents in Munshiganj and Buri Gualini have reported a higher proportion of households having debt $(46.2 \%$ in both cases) than the other two unions. However, non-capability of loan repayment is only higher in Buri Gualini (nearly $40 \%$ ) compared to the other three unions. Largely, Buri Gualini has shown the most increased vulnerability on the socio-demographic profile index among the four unions (SDPBuri Gualini 0.323642; SDPIshwaripur 0.315638; SDPGabura 0.310834, and SDPMunshiganj 0.309164). The socio-demographic vulnerability mean score was not statistically different among the four unions.

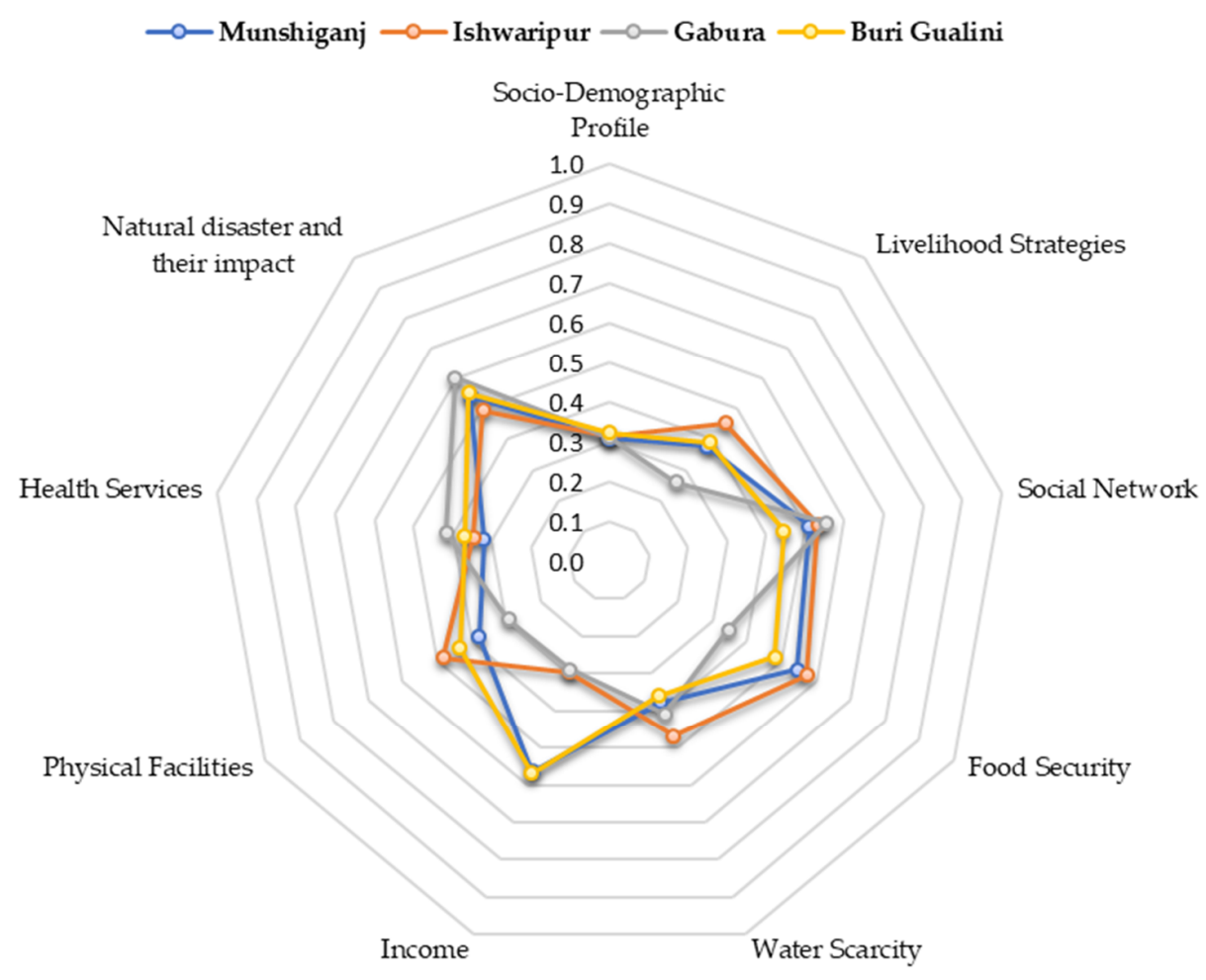

Figure 4. Vulnerability spider diagram of the major components of the livelihood vulnerability index (LVI) for Shyamnagar Upazila (sub-district), Bangladesh.

Ishwaripur has shown greater vulnerability on the livelihood strategies component (0.452986) than the other three unions of Ishwaripur (0.389957), Gabura (0.259022), and Munshiganj (0.378077). The livelihood diversification index was the highest in Buri Gualini (0.688889) and the lowest in Gabura (0.374359). The percentage of changing cropping strategies was recorded as relatively lower in all 
four unions compared with the other components' index value. Less than $20 \%$ of the total households have decided to undertake new farming strategies in each union; strategies have not changed in Buri Gualini during the survey time. Note that, in comparison with the mean $(p<0.05$ level) for Buri Gualini, for Ishwaripur, Gabura, and Munshiganj we found a statistically significant difference for livelihood strategies.

The social networks indicators were approximately similar for all four unions. The average help ratio is relatively equal for all unions, although the highest value of help received was four, and the lowest value was 0 . Nearly $60 \%$ of the total households in Ishwaripur, Gabura, and Munshiganj have mentioned that they have not been approached by their local government for assistance in the past few months. However, the percentage of total households that have reportedly asked for help from the local government in Buri Gualini is relatively lower than the other three unions (33.3\%). Overall, Gabura has the highest social network vulnerability score (0.553953), whereas the lowest social network vulnerability index was in Buri Gualini (0.444231). The mean vulnerability score in the social network component was not statistically significant.

Households in Gabura have reported that they have been struggling to find adequate food for their families for an average of 0.66 months per year in comparison to the other three unions (Munshiganj, 0.462; Ishwaripur, 0.436; and Buri Gualini, 0.462). A higher percentage (more than $60 \%$ of total households) of all the unions have reported an inability to save harvested crops for consumption for the rest of the year. Additionally, Ishwaripur has a higher vulnerability index (0.571622) in the food component than the other three unions (Munshiganj, 0.544441; Buri Gualini, 0.480203; and Gabura, 0.345064). However, the mean index score among the four unions was different but not statistically significant.

The Ishwaripur households reported a higher percentage (74.4\%) of not having access to safe drinking water than the other three unions (Munshiganj, 53.8\%; Gabura, 43.6\%; and Buri Gualini, $46.2 \%)$. In the case of accessing safe drinking water, the Ishwaripur households reported that they had to travel an average of $1.23 \mathrm{~km}$ distance to collect safe water, while the average travelling distance was the lowest $(0.456 \mathrm{~km})$ in Gabura. The households of the other unions, Munshiganj and Buri Gualini, had to travel an average of $0.969 \mathrm{~km}$ and $0.459 \mathrm{~km}$, respectively, to obtain safe drinking water. However, households in Gabura (59\%) reported scarcity of water for a whole year, compared to the other unions. The average money spent on the families to receive safe drinking water in a month was quite similar in all unions. The overall vulnerability score of the water component was the highest in Ishwaripur (0.469293), while Buri Gualini had the lowest index score (0.360482). The water scarcity score for Buri Gualini, Ishwaripur, Gabura, and Munshiganj were found statistically significant ( $p<0.05$ level).

Munshiganj and Buri Gualini had a greater vulnerability index in the income component than the other two unions. A higher percentage of the households (59\%) in Ishwaripur had reported a loss of income due to climate change and climate extremes, but the average months where households were without income during cyclone Aila were the highest in Munshiganj (3.385). A higher percentage of the households in both Munshiganj (79.5\%) and Buri Gualini (82.1\%) experienced income and asset loss because of robbery, while the other two unions reported less than $10 \%$ similar cases. Comparison of the income vulnerability index ( $p<0.05$ level) for Buri Gualini, Ishwaripur, Gabura, and Munshiganj were found to be statistically significant.

Ishwaripur had a greater vulnerability index in the case of accessing physical facilities $(0.483757)$ than the other three unions (Munshiganj, 0.378032; Gabura, 0.291802; and Buri Gualini, 0.434611). A higher percentage of the households in Ishwaripur (74.4\%) and Gabura (74.4\%) reported limited or no access to good hospitals for their treatment than the other unions. The average time to reach the nearest vehicle station is the highest in Ishwaripur (nearly $30 \mathrm{~min}$ on average) while it is the lowest in Gabura (less than $8 \mathrm{~min}$ ). In the case of the health-related sub-component's, the obtained values are quite similar in all four unions, and the health vulnerability index is close to each other. The difference between the highest and lowest health vulnerability index is 0.415354 and 0.346215 , 
respectively. Comparison of the vulnerability mean index score between the four unions in respect of physical facilities and health facilities components was found to be significant ( $p<0.05$ level).

All the unions had quite similar natural disaster vulnerability scores, based on the average reported number of natural hazards in the past ten years. A natural disaster vulnerability index for Gabura (0.603144) showed a higher vulnerability than the other unions (Munshiganj, 0.543199; Ishwaripur, 0.494719; and Buri Gualini, 0.551541). A comparison of the natural disaster vulnerability scores between Gabura, Munshiganj, Ishwaripur, and Buri Gualini was found to be significant $(p<0.05$ level).

Moreover, Ishwaripur has a higher LVI (0.437326) than the other three Unions (Munshiganj, 0.426367; Gabura, 0.403680; and Buri Gualini, 0.429341), indicating relatively moderate vulnerability for all the four Unions to climate-induced stresses. The results of the major component calculations are presented collectively in a spider diagram (see Figure 3). The scale of the diagram ranges from 0 (less vulnerable) at the center of the web, increasing to 0.5 (more vulnerable) at the outside edge in 0.1-unit increments. Figure 3 shows that Ishwaripur is more vulnerable in terms of socio-demographic profile, livelihood strategies, water, and physical facilities, while Gabura is more vulnerable in terms of natural disasters, food, and social network components. Munshiganj and Buri Gualini have a greater vulnerability in terms of income component. However, comparisons of the overall livelihood vulnerability mean index scores (LVI) amongst the four communities were not statistically significant $(\mathrm{F}=0.919, p>0.05)$.

Figure 5 shows the major components contributing to livelihood vulnerability amongst the four rural communities. The diagram reflects the fact that Ishwaripur is more vulnerable in most components, in particular to livelihood strategies, social network, food security, water scarcity, and physical facilities, whereas Gabura is slightly more vulnerable for natural disasters and their impacts, as well as for the health services components. Furthermore, Munshiganj and Buri Gualini are more vulnerable towards the income and socio-demographic profile components, respectively, than the other two unions.

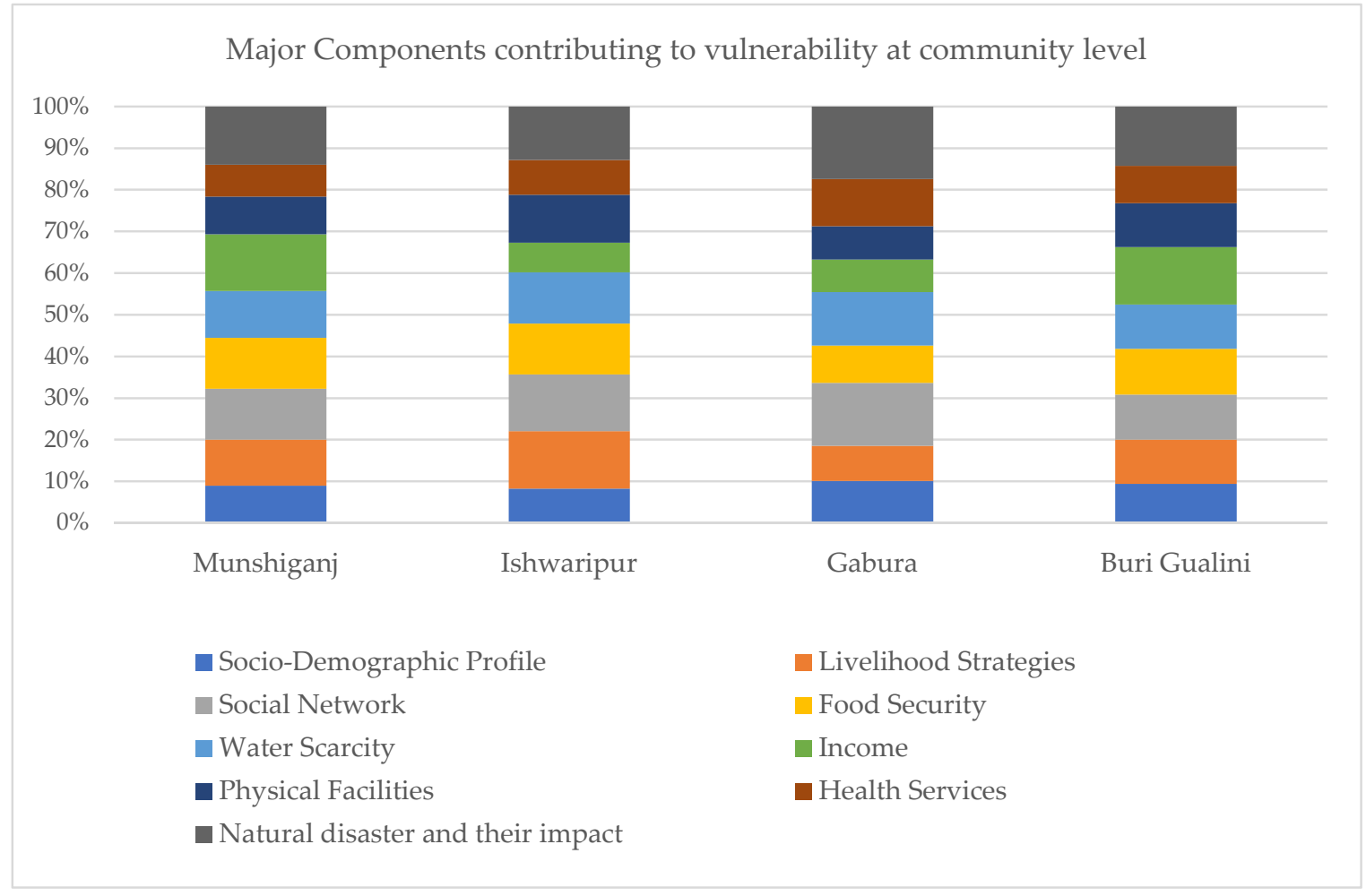

Figure 5. Components contributing to the vulnerability of the four rural communities. 


\subsection{Nature and Extent of Household Vulnerability to Climate-Induced Stresses}

Three household clusters were explored from the analysis of the livelihood vulnerability index: (i) less vulnerable households who can cope the vulnerable situation; (ii) moderately vulnerable households who require temporal assistance for coping climate-induced shocks or stresses; and (iii) the most vulnerable who needs to be targeted for mobilizing assets to adapt immediately [31]. The result shows that many households fall within the moderate vulnerable category (88 out of 156 sampled households). The less vulnerable households constitute $21 \%$ ( 32 households), while the most vulnerable households have $23 \%$ of the total outcome (see Figure 6 for details).

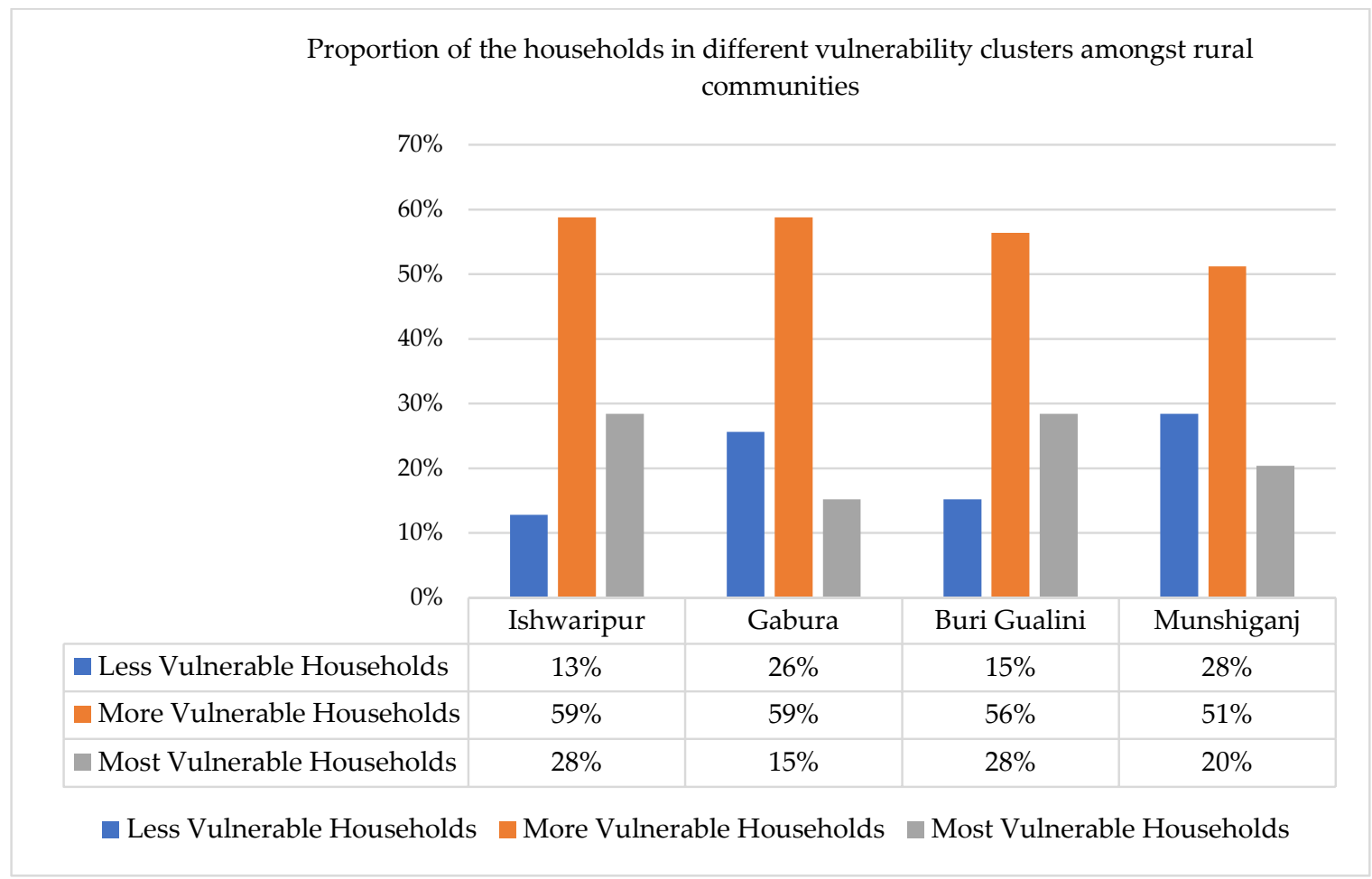

Figure 6. The proportion of households in different vulnerability clusters in the four unions.

The percentage of rural households in all the studied unions, Ishwaripur (58.8\%), Gabura (58.8\%), Buri Gualini (56.4\%), and Munshiganj (51.2\%), are primarily found within the moderate vulnerable category. Among the four unions, Ishwaripur and Buri Gualini both have the highest percentage of a highly vulnerable population (28.4\%), and the rest are from the other unions, including Gabura $(15.2 \%)$ and Munshiganj (20.4\%). Although there seems to be a normal vulnerability index distribution in Figure 6, a close look at the values shows a slight shift to the right. The households' vulnerability distribution is skewed toward higher vulnerability. In general, the results reveal moderate vulnerability levels amongst rural households across the study area.

From Figure 7, it depicts that all the hundred and fifty-six households' vulnerability index is different from each other. At the time of adaptation planning, it is essential to consider each household's LVI score. Comparing household level LVI with other households may reveal a distinct difference. We have considered two households from the lower vulnerable category to compare and contrast households' vulnerability: one household had an LVI score of 0.376798 , which is the upper limit of the lower vulnerable category; whereas another household obtained an LVI score of 0.286549 , which is within the lower limit of the lower vulnerable category (see Figure 4 and Supplementary Table S5 for details). Although these two households are existing in the lower vulnerable category, there is a significant difference. While comparing the level of vulnerability of the two households in the case of lower vulnerable category, three major components, namely, socio-demographic profile 
(SDP), livelihood strategies (LS), and social networks (SN) under the adaptive capacity dimension, were considered. In the case of socio-demographic profile (SDP), the dependency ratio index was 0.285714 for the lowest vulnerable household, whereas the ratio was 0.428571 for the highest vulnerable household within the lower category. In Munshiganj, the minimum LVI-scored households have reported a higher index value upon considering girls aged 10-19 years, a female member with no functional education, debt, disability and dependency, and education of the household head. Moreover, it revealed that other components may be more reliable than a socio-demographic profile to increase or decrease the vulnerability level within the less vulnerable category of Munshiganj. In the case of livelihood strategies, the household with a minimum LVI score has shown lower vulnerability on the LS index than the household with a maximum LVI score (LSmin 0.291667 and LSmax 0.391667), which is different from SDP. Therefore, the maximum LVI-scored household has moved into a highly vulnerable category because of the social network (SN) component.

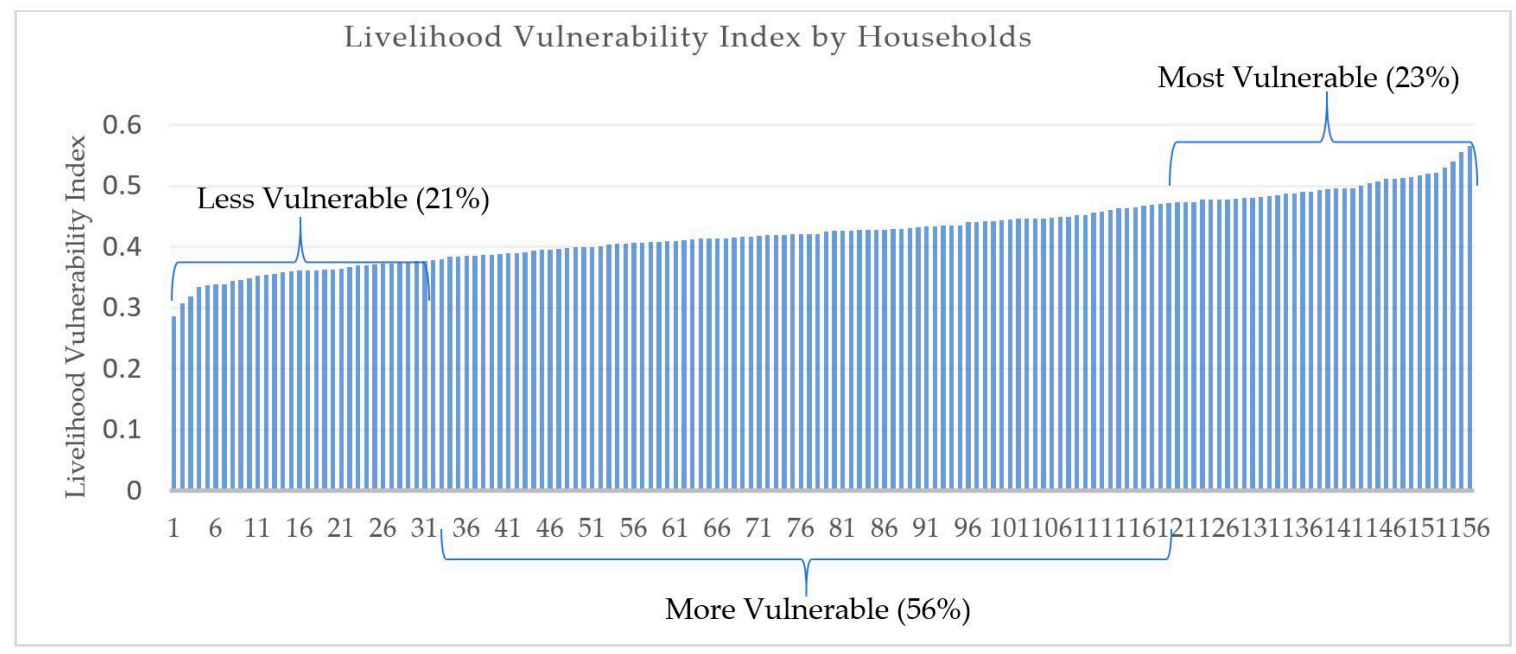

Figure 7. Vulnerability index by households in four rural communities of Shyamnagar Upazila.

For further characterizing the vulnerability clusters, we have used the poverty level of the rural households, which is understood as the state of having little or no money and few or limited assets [48]. Considering the income-based definition of poverty, we have determined two poverty scenarios by using the World Bank's SDG threshold of 1.9 US\$ per capita per day [49]. As per this consideration, poor households are those who have a per capita income of 1.9 US\$ and less per day (i.e., poor $=<1.9$ US\$ pcpd), while non-poor households are those who have higher per capita income per day (i.e., non-poor $\geq 1.9$ US\$ pcpd). Figure 8 shows the proportion of poor and non-poor households within the three vulnerable categories.

Figure 8 reveals that a higher proportion of the non-poor population (nearly $70 \%$ ) falls within the moderately and highly vulnerable groups, while only $9.7 \%$ of total poor households have been found within the higher vulnerability groups. Although $2.6 \%$ of households are poor, they can cope with climate-induced shocks and stresses. While a large number of non-poor households fall within the higher vulnerability, it is essential to explore the most deserving households or outlier households [30] who need assistance for adaptation. As a result, it is emergent to examine the nature of the vulnerability of the outlier households at the housing-unit level. In doing so, we are attempting to develop a nexus between the LVI and asset deprivation index. 


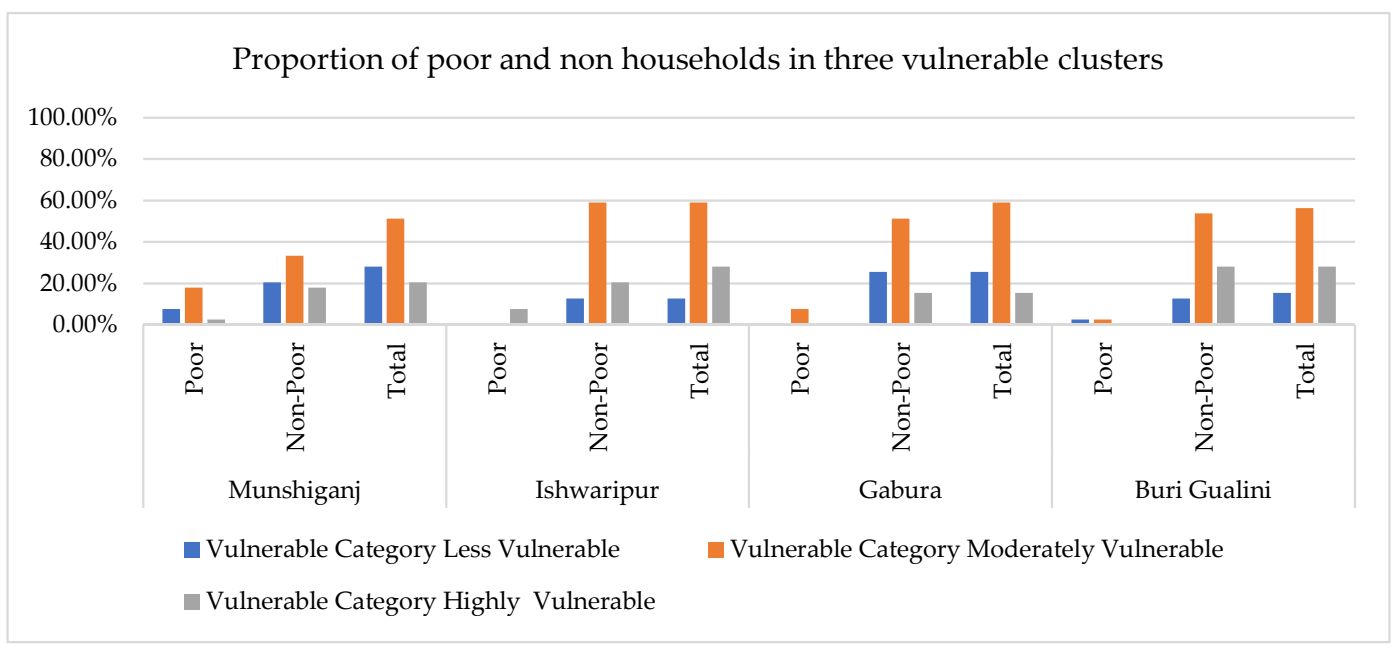

Figure 8. Household vulnerable clusters by poverty categories.

\subsection{Nexus between Livelihood Vulnerability and Poverty}

Analysis of the household-level vulnerability index reveals the differences and similarities in the vulnerable category under a given set of criteria. Nonetheless, it is essential to make a few strata of vulnerability so that the policymakers can target these clusters to generate adaptation strategies related to climate-induced stressors. As a result, this research builds the nexus between livelihood vulnerability and poverty. In this regard, the asset-based framework was used to measure the asset deprivation index that helps to categorize different categories of poverty. By using the asset-based approach [50], the poor are characterized by having limited assets and low returns from these limited assets, and they are often unable to utilize their resources effectively.

Additionally, they have not only a limited capacity to accumulate a portfolio of assets but also a lack of choices regarding alternative coping strategies [51]. Considering the asset-based framework [52-56], this research identified forty indicators regarding asset deprivation under five dimensions, namely, human assets, natural or agricultural assets, social assets, physical assets (i.e., land and building), and financial assets, to generate the asset deprivation index (see Table S8 for details). Based on the asset deprivation index, three poverty categories were identified, and those include moderately poor (0.340-0.469), poor (0.470-0.597), and extremely poor (0.598-0.726) [41].

Several households among the four unions were mostly distributed into the poor and extremely poor categories as their asset deprivation index value was $>0.46$, and each union's average was $>0.5$. Only $8.97 \%$ of total households are considered as moderately poor, because their asset deprivation index value is $<0.47$. In Gabura, the average asset deprivation index (0.593703) is the highest among the four unions, and it is the highest in each of the asset categories except for human capital assets. The human capital deprivation index is slightly higher in the Buri Gualini union (0.67993) than that of Gabura (0.625067). The livelihood asset deprivations were statistically different between unions with respect to the following asset components (see Figure 9 for details): no vocational training $(p \leq 0.001)$; health status ( $p \leq 0.001)$; having agriculture land ( $p \leq 0.05)$; no access to fishing ( $p \leq 0.001)$; access to forest-based energy for cooking purpose ( $p \leq 0.05$ ); no access to khas (public) land ( $p \leq 0.001$ ); frequency of visits in Sundarbans or sea last year ( $p \leq 0.001)$; having no chicken/ducks ( $p \leq 0.10)$; having no goats ( $p \leq 0.001)$; having no cattle/cow ( $p \leq 0.001)$; limited vertical linkages ( $p \leq 0.05)$; having access to old-age allowances ( $p \leq 0.05)$; not having television or radio $(p \leq 0.05)$; no access to mobile phone $(p \leq 0.05)$; decreased quality of drinking water $(p \leq 0.001)$; no access to available transport $(p \leq 0.001)$; HH having bicycle house affected by cyclone ( $p \leq 0.001)$; not having cyclone shelter near to the house $(p \leq 0.001)$; not having solar energy as a source of electricity $(p \leq 0.001)$; access to micro-finance of NGOs ( $p \leq 0.05)$; amount of cash savings ( $p \leq 0.001)$; having savings in the bank $(p \leq 0.001)$; and no regular inflows of money: remittance $(p \leq 0.10)$. 


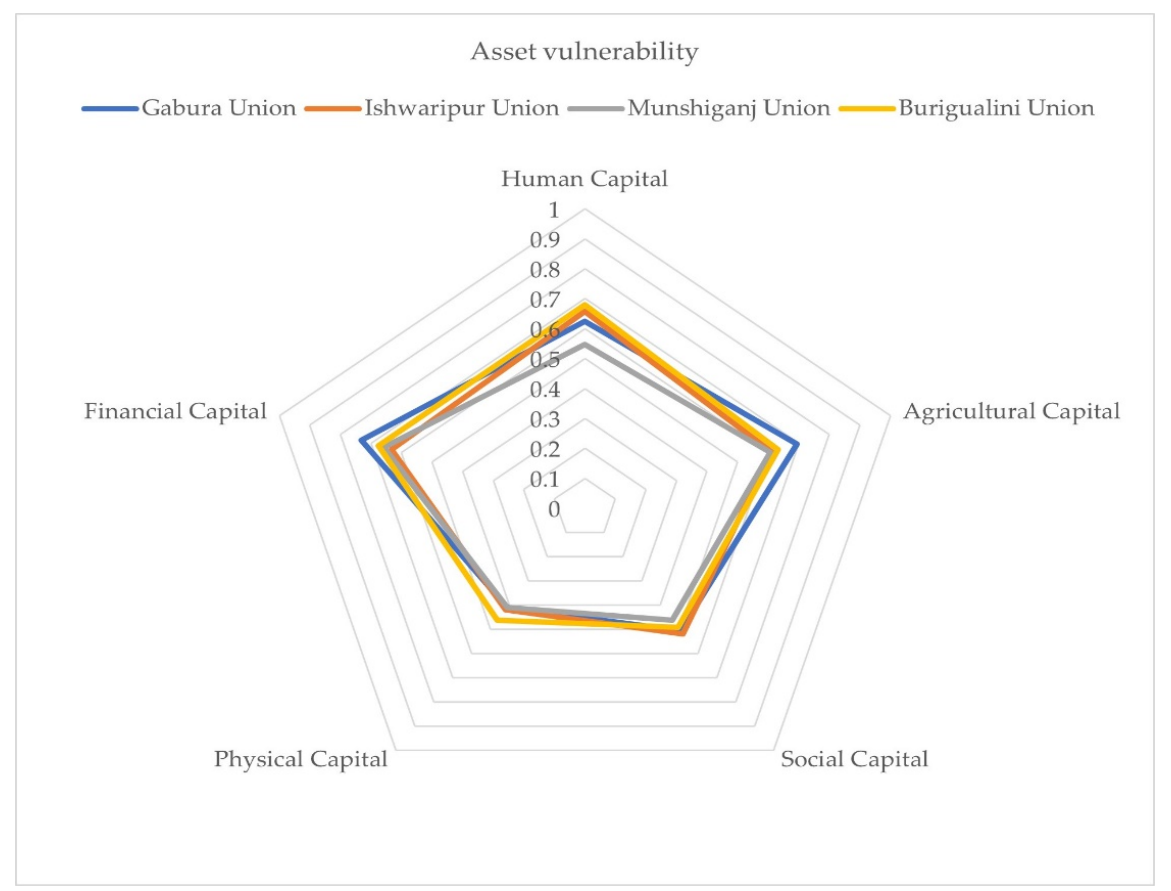

Figure 9. Asset deprivation index for rural communities.

Upon integrating the livelihood vulnerability index (LVI) scores and asset deprivation index (ADI) scores, we explored nine different strata (see Figure 10 for details). Note that each type of poor category has three different sub-categories. For instance, extremely poor households are found low vulnerable, moderate vulnerable, and highly vulnerable. However, asset deprivation of all the extremely poor households is the highest among all three poverty categories. Some of them have lower LVI scores that make them least vulnerable in comparison to extremely poor and moderately poor households. Alternatively, some moderately poor who have the least asset deprivation among the three categories of households were found highly vulnerable to climate-induced stressors. In terms of vulnerability and asset deprivation or the poverty differential index, a household can be categorized under any of these nine sub-categories, where each category requires differential treatment and additional policy measures according to the poverty level.

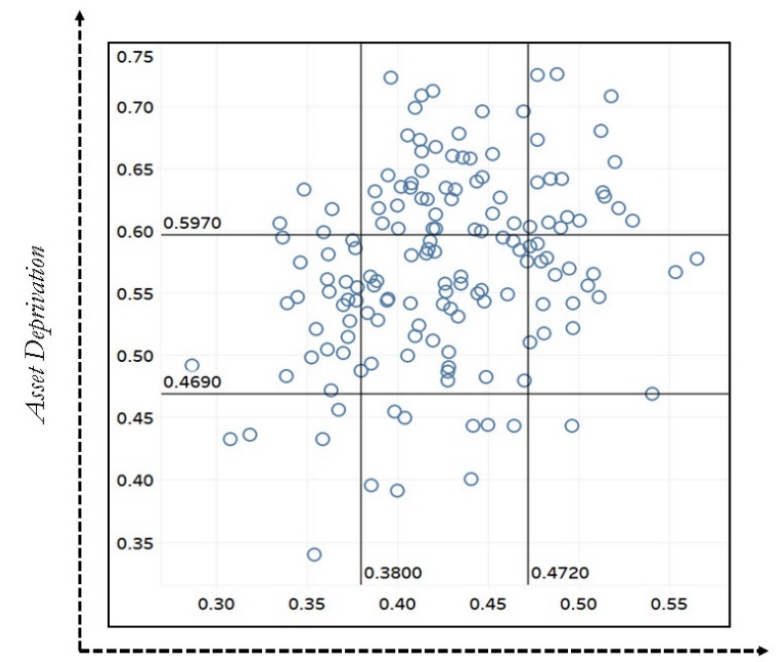

Livelibood Vulnerability

Figure 10. Juxtaposing the asset deprivation index and livelihood vulnerability index. 


\section{Discussion}

An analysis of community vulnerability indexing suggests that the vulnerability differences among the four rural communities are minimal, as they were not statistically significant. Similar findings are spotted while analyzing community-level vulnerability. This community vulnerability indexing has been reported in previous studies as well [57-59]. The sampled households in all the four rural communities have been highly affected by multiple hazards, such as floods, cyclones, salinity, and droughts, as the average number of natural disasters experienced by the households are nearly 4 . An index analysis reveals that a higher percentage of the population in all four unions have experienced damage to their houses and crops, loss of livestock, suffered occupation, and waterlogging in the homestead for a long duration. Note that many agricultural lands in the study area have been severely affected by salinity intrusion and thus rendered no cultivation immediately after cyclone Aila and later converted into shrimp farming (local name is gher), which reduces the demand of labors in this sector [60]. Therefore, a greater vulnerability index for all four unions has been determined in the NDI component. The households amongst all the unions are moderately sensitive to food, water, income, physical facilities, and health. However, the difference in the mean vulnerability index for water, physical income facilities, and health components between the four unions were found to be statistically significant. Interestingly, a large number of households in Munshiganj and Buri Gualini have lost their income due to robbery that influenced differential income vulnerability between the four unions. Households' differential accessibility to physical infrastructures or facilities, such as primary schools, cyclone centers, vehicle stations, and health centers, mainly creates differences at the community-level vulnerability. Theoretically, the influence of exposure and sensitivity components on livelihood vulnerability may be diminished by practicing the adaptive capacity of the households. However, horizontal and vertical linkages of the households amongst the four unions are limited as households' membership either in the community-based organizations or GOs and NGOs programs were found limited. Although a significant difference was found in the households' livelihood strategies amongst the four unions, major indicators such as the livelihood diversity index and members' working outside ratio are relatively lower amongst all four unions. The only difference between the four unions was found in loan debt and repayment, which influence the vulnerability score of this component. Furthermore, the socio-demographic profile score is quite similar for all four unions. Many female-headed households, single-headed elderly households, and illiterate households who have a relatively higher vulnerability to climate change, were found across the study area, which influences the overall LVI to some extent. The community-level vulnerability analysis suggests that households amongst four unions fall into the moderately vulnerable category; but, many of the sampled households are in the highly vulnerable category. Therefore, upon analyzing the household level vulnerability, the analysis reveals a new policy area for pro-poor adaptation planning. The following section explains this issue.

Household vulnerability analysis was performed in three steps. In step one, we have developed a household-level LVI and distributed it into three vulnerable clusters, which suggest household-level vulnerability is right-skewed, and a higher proportion of the population was distributed into the moderately vulnerable strata. However, it is also revealed that each household vulnerability is unique and needs to be compared with each other. By examining each of the lower household vulnerability scores, $34 \%$ of the households have a high score $(\geq 0.706)$ considering livelihood strategies, social network, income, and natural disasters and their impacts. In the highly vulnerable category, most of the households (92\%) have a higher vulnerability score considering seven components, except socio-demographic and health components. However, it may be difficult for policymakers to consider each of the household's vulnerability indices and build appropriate incentive packages for a wide range of the population in the community. To identify outlier households, we follow the second and third steps. In the second step, descriptive statistics suggest that a higher proportion of households amongst the four unions are non-poor, and they tend to fall into a moderately and highly vulnerable category. Only $10 \%$ of total households were found to be outlier households by using the 
income poverty measure, while many households who live near the poverty line of 1.9 US\$ pcpd fall into higher vulnerable groups. Therefore, an asset-based analysis is optimum and may be able to identify and characterize outlier households. By interpolating household asset deprivation into vulnerability, we have found three blocks as 'outliers' as their vulnerability score, and asset score are relatively higher than others, and three blocks are considered as 'resilient' although they have a higher proportion of livelihood vulnerability to climate-induced stresses [30] (see Figure 11 for details).

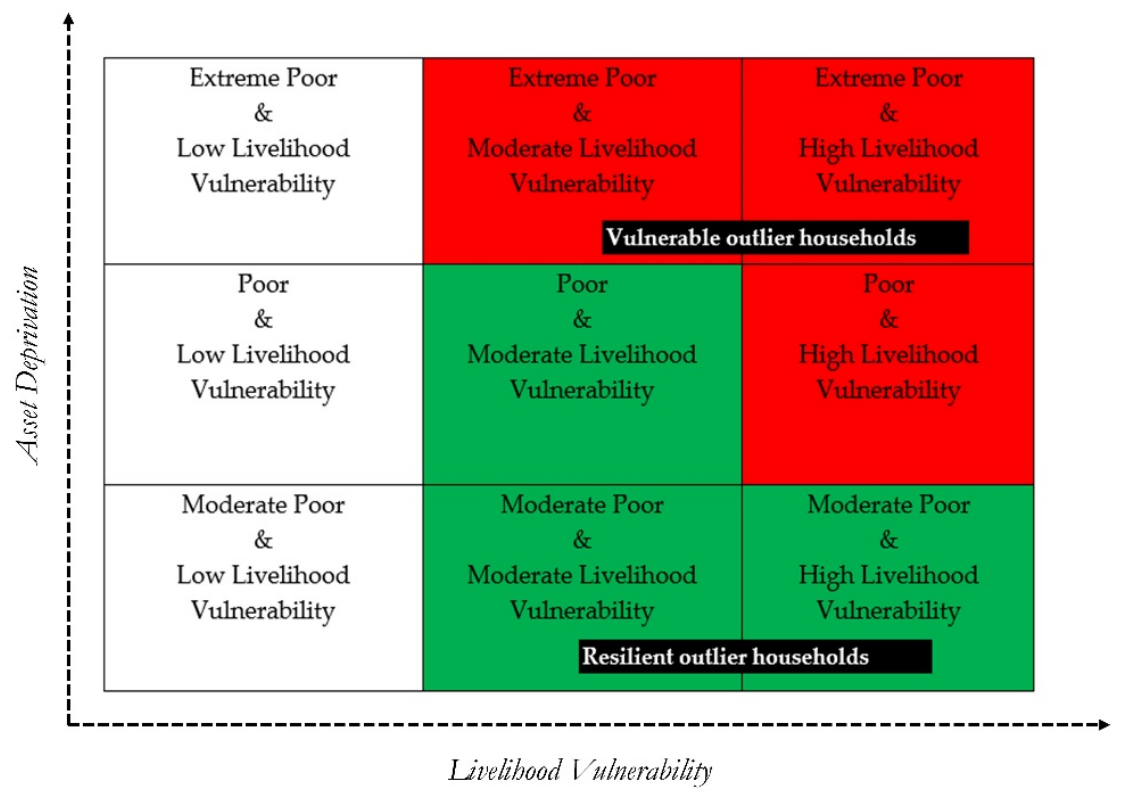

Figure 11. Nexus between assets and vulnerability.

The households become considered as outliers when they have multiple asset deprivations at a time. Households might be outliers when they have no or limited human capital assets that include vocational training and poor health status; limited access to natural capital assets (i.e., limited access to natural capital assets, for example, agriculture land, no access to fishing, and little access to forest-based energy for cooking purpose); no access to khas land; limited access to Sundarbans resources in the last year, and having no livestock; limited horizontal and vertical linkages; having no or limited ownership of the physical asset; and limited access to savings, remittances, and institutional credit services. The "vulnerable outlier households" were found in almost all types of assets (social and physical), which make them the least able to withstand climate-induced shocks and stresses. In the case of "resilient outlier households", having ownership of one or more assets makes them resilient. For human capital assets, households that have disaster management training and a skilled workforce in the family can reduce the vulnerability of the households, which is significant. Having ownership of natural capital assets, such as agricultural land, may minimize household vulnerability, which is found significant in this case as well. Besides, access to fishing was also found as significant, differentiating outlier and resilient households. Access to savings can reduce vulnerability and make households more resilient. Access to safe drinking water pulls households into a resilient category and reduces the risk of falling into the outlier category. Although vertical linkages of households are limited, households who have got access to government safety nets or NGOs or community-based committees are considered as resilient households.

\section{Conclusions}

This research develops and applies the livelihood vulnerability index for contrasting household-level vulnerability to climate-induced stresses at different communities. The overall analysis of livelihood vulnerability to climate change has revealed that most of the sampled households 
amongst four unions are highly affected by natural disasters. Several factors, such as waterlogging, high salinization of agricultural land, frequent drought, decrease in fish production, and limited access to resources of Sundarbans, largely influence the livelihood vulnerability of these households. Besides, scarcity of drinking water, the spread of diseases, and inadequate medical facilities, as well as loss of income due to robbery, have increased the sensitivity of households considering climate change. Furthermore, households' limited access to horizontal and vertical linkages have influenced them to become the least capable of coping with climate-induced stresses.

The results of household-level vulnerability on the LVI generated by scholars [19,40-42] have provided a more nuanced understanding of the potential impacts of climate-induced stresses. The household-level findings are more dynamic than regional- and community-level vulnerability analyses, which consider social, economic, environmental, and physical factors for demonstrating comparisons. In contrast to a regional- or community-level LVI analysis, the household-level LVI analysis has revealed that the existence of variability among households in each union is similar in nature. While measuring the LVI at the regional level, Hahn and colleagues [19] have asserted that many of the LVI sub-components, including livelihood strategies, demographic structures, and access to water and health facilities, have discerned similarities among the households within a particular region. However, we have already demonstrated that differences in these sub-components, such as livelihood strategies, demographic structures, access to water, and health facilities among the households within a union (see Supplementary Tables S5-S7 for details), are still prominent. These differences are often ignored at the regional level, but it requires to be accounted for developing targeted interventions for safety nets, relief aid and rehabilitation, and for livelihood adaptation. There is always a chance of missing out on these households in the targeted interventions if we only focus on higher-level spatial analysis while generating policies. We will also fail to address diverse household requirements for adaptation planning if we do not consider individuals at the community level.

This research contributes to existing theoretical debates on demonstrating relationships between vulnerability and assets by enhancing the framework considering livelihood, vulnerability, and assets at the household level in the time of climate-induced stresses in coastal areas of Bangladesh. The analysis helps to set up strategies for the poor vulnerable people to be more resilient. The household-level analysis reveals that the effectiveness of asset endowments in building resilience among vulnerable households is critical. The asset endowments incorporate skilled manpower in the family, disaster management training, livestock holdings, land ownership, savings and remittances, access to credit facilities, and access to safety net programs. This opportunity can make vulnerable households more resilient, which resonates with findings of some hazard or disaster risk reduction studies in the contemporary scientific literature [58-63]. We have also found few contrasting outlier households to the prior ones who are categorized as the "vulnerable outlier households". These households are characterized by limited access to human, natural, social, physical, and financial capital assets. Therefore, the vulnerable outlier household clusters require the highest priority in terms of crisis management as their asset deprivations are high with a high and moderate level of vulnerability.

Consequently, this research opts to develop a nexus between livelihood, vulnerability, and assets. The results demonstrate that plenty of scopes are in place to make communities more resilient to climate-related stress in the coastal areas. The research also suggests that assets are differential amongst rural households, which often make the disparity of the coping capacity of the households to bounce back from the negative effects of climate-induced hazards. Because of the differential coping capacity amongst the rural households, some are sliding into the vulnerable outlier category, and some have the capacity to bounce back from climate-induced shocks and stresses. This research provides a clear indication of the seemingly overlapping relationship between vulnerability and resilience. Furthermore, it has demonstrated a systematic understanding of vulnerability, livelihood, and assets, which may be an integrated narrative for adaptation planning to climate-induced stresses in the global south. 
An appropriate scale that can be used in the assessment of livelihood vulnerability poses a big challenge for scientists and researchers. Hahn and colleagues [19] have emphasized the objective of a vulnerability assessment to have a choice of scale. We have selected similar communities that are the most vulnerable to climate change and climate extremes for an analysis of LVI. The purpose of this analysis is to characterize vulnerable households considering social, economic, physical, environmental, and political components. Moreover, we aim to establish community-level vulnerability analysis at the household level to document them appropriately in the uncertain risks of climate change and climate extremes in the global south. We conceptualize household livelihood vulnerability by three dimensions-exposure, sensitivity, and adaptive capacity, which are widely used in assessing vulnerability to climate change and disasters [19,21-23,40-42]. Furthermore, we recommend that the generated model should be tested elsewhere in the global south, considering the socio-economic conditions prior to employing it in reality.

Supplementary Materials: The following are available online at http://www.mdpi.com/2673-4060/1/2/12/s1, Table S1: Land use/cover change between 2010 and 2008; Table S2: Variable selection under major component for livelihood vulnerability index (LVI); Table S3: A big table of major components, variables (sub-components), and average index values of four Union and their LVI values; Table S4: Livelihood vulnerability index (LVI) sub-component values and minimum and maximum sub-component values for Four Union; Table S5: Distribution of the households' LVI within the lowly (or less) vulnerable category; Table S6: Distribution of the households' LVI within the moderately vulnerable category; Table S7: Distribution of the households' LVI within highly vulnerable category; Table S8: Dimensions and variables and their unit of measurement for constructing asset deprivation index; Table S9: ANOVA and Chi-squared test to understand significant difference of mean and frequency of different variables between study communities (or four unions).

Author Contributions: Conceptualization and methodology, M.M., M.Z.H., K.R.R. and N.M.H.-M.; data processing and summarization, M.M., M.Z.H., K.R.R. and N.M.H.-M.; writing draft, M.M., M.Z.H., K.R.R. and N.M.H.-M.; final editing, M.Z.H. and K.R.R.; supervision, M.Z.H. and K.R.R. All authors have read and agreed to the published version of the manuscript.

Funding: The research project did not receive any funding source.

Conflicts of Interest: The authors declare no conflict of interest.

\section{References}

1. IPCC (Intergovernmental Panel on Climate Change). Climate Change 2007: Impacts, Adaptation, and Vulnerability; Cambridge University Press: Cambridge, UK, 2007.

2. Bernstein, M.; Young, S.; Hugenberg, K. The cross-category effect. Psychol. Sci. 2007, 18, 706-712. [CrossRef] [PubMed]

3. Adger, W.; Paavola, J.; Huq, S.; Mace, M.J. (Eds.) Fairness in Adaptation to Climate Change; The MIT Press: Cambridge, MA, USA, 2006.

4. IPCC (Intergovernmental Panel on Climate Change). Climate Change 2001: Impacts, Adaptation, and Vulnerability; Cambridge University Press: Cambridge, UK, 2001.

5. Adger, W.N.; Huq, S.; Brown, K.; Conway, D.; Hulme, M. Adaptation to climate change in the developing world. Prog. Dev. Stud. 2003, 3, 179-195. [CrossRef]

6. Birkmann, J. Measuring Vulnerability to Promote Disaster-Resilient Societies: Conceptual Frameworks and Definitions. 2006. Available online: https://pdfs.semanticscholar.org/c5d7/ 618e26e587f1c1a0f4afc4c8ff1926a1634f.pdf (accessed on 27 March 2020).

7. Coirolo, C. Climate change and livelihoods in Northwest Bangladesh: Vulnerability and Adaptation among Extremely Poor People. Ph.D. Thesis, University of Sussex, Brighton, UK, 2013.

8. Adger, W.N. Social and ecological resilience: Are they related? Prog. Hum. Geogr. 2000, 24, 347-364. [CrossRef]

9. Adger, W.N. Social vulnerability to climate change and extremes in coastal Vietnam. World Dev. 1999, 27, 249-269. [CrossRef]

10. Sen, A. Poverty and Famines: An Essay on Entitlement and Deprivation; Clarendon Press: Oxford, UK, 1981.

11. Swift, J. Why are rural people vulnerable to famine? IDS Bull. 1989, 41-49. [CrossRef]

12. Anderson, M.B.; Woodrow, P.J. Rising from the Ashes: Development Strategies in Times of Disaster; Routledge: New York, NY, USA, 1989. 
13. Smith, K. Environmental Hazards: Assessing Risk and Reducing Disaster; Routledge: New York, NY, USA, 2003.

14. O'Keefe, P.; Westgate, K.; Wisner, B. Taking the naturalness out of natural disasters. Nature 1976, $260,566-567$. [CrossRef]

15. Hewitt, K. (Ed.) Interpretations of Calamity from the Viewpoint of Human Ecology; Allen \& Unwin Inc.: Boston, MA, USA, 1983.

16. Mustafa, D. Structural causes of vulnerability to flood hazard in Pakistan. Econ. Geogr. 1998, 74, $289-305$. [CrossRef]

17. Blaikie, P.; Cannon, T.; Davis, I.; Wisner, B. At Risk: Natural Hazards, People's Vulnerability, and Disasters; Routledge: London, UK, 1994.

18. IPCC (Intergovernmental Panel on Climate Change). Climate Change 2014: Impacts, Adaptation, and Vulnerability; Cambridge University Press: Cambridge, UK, 2014.

19. Hahn, M.B.; Riederer, A.M.; Foster, S.O. The Livelihood vulnerability index: A pragmatic approach to assessing risks from climate variability and change-A case study in Mozambique. Glob. Environ. Chang. 2009, 19, 74-88. [CrossRef]

20. Pandey, R.; Jha, S. Climate vulnerability index-measure of climate change vulnerability to communities: A case of rural Lower Himalaya, India. Mitig. Adapt. Strateg. Glob. Chang. 2012, 17, 487-506. [CrossRef]

21. Fernandez, P.; Mourato, S.; Moreira, M. Social vulnerability assessment of flood risk using GIS-based multicriteria decision analysis. A case study of Vila Nova de Gaia (Portugal). Geomat. Nat. Hazards Risk 2016, 7, 1367-1389. [CrossRef]

22. Gerlitz, J.-Y.; Macchi, M.; Brooks, N.; Pandey, R.; Banerjee, S.; Jha, S.K. The multidimensional livelihood vulnerability index-An instrument to measure livelihood vulnerability to change in the Hindu Kush Himalayas. Clim. Dev. 2017, 9, 124-140. [CrossRef]

23. Rahman, M.M. Community Perceptions and Adaptation to Climate Change in Coastal Bangladesh. Ph.D. Thesis, Curtin University, Bentley, Australia, 2014.

24. Panthi, J.; Suman, A.; Dahal, P.; Parashuram, B.; Nir, K.; Vishnu, P. Livelihood vulnerability approach to assessing climate change impacts on mixed agro-livestock smallholders around the Gandaki River Basin in Nepal. Reg. Environ. Chang. 2015, 16, 1121-1132. [CrossRef]

25. Piya, L.; Maharjan, L.K.; Niraj, J. Vulnerability of rural households to climate change and extremes: Analysis of Chepang households in the Mid-Hills of Nepal. In Proceedings of the International Association of Agricultural Economists (IAAE) Triennial Conference, Foz do Iguaçu, Brazil, 18-24 August 2012.

26. Madu, I. Spatial vulnerability of rural Nigeria to climate change: Implications for internal security. Int. J. Clim. Chang. Strateg. Manag. 2012, 3, 79. [CrossRef]

27. Vincent, K. Creating an Index of Social Vulnerability to Climate Change for Africa. 2004. Available online: https://www.researchgate.net/profile/Katharine_Vincent/publication/228809913_Creating_an_Index_ of_Social_Vulnerability_to_Climate_Change_in_Africa/links/546478a50cf2c0c6aec52194.pdf (accessed on 20 March 2020).

28. Khajuria, A.; Ravindranath, N.H. Climate change in context of Indian agricultural sector. J. Earth Sci. Clim. Chang. 2012, 3, 110. [CrossRef]

29. Žurovec, O.; Čadro, S.; Sitaula, B.K. Quantitative Assessment of Vulnerability to Climate Change in Rural Municipalities of Bosnia and Herzegovina. Sustainability 2017, 9, 1208. [CrossRef]

30. Antwi-Agyei, P.; Dougill, A.J.; Fraser, E.D.G.; Stringer, L.C. Characterising the nature of household vulnerability to climate variability: Empirical evidence from two regions of Ghana. Environ. Dev. Sustain. 2012, 15, 903-926. [CrossRef]

31. Opiyo, F.E.; Wasonga, O.V.; Nyangito, M.M. Measuring household vulnerability to climate-induced stresses in pastoral rangelands of Kenya: Implications for resilience programming. Pastoralism 2014, 4, 10. [CrossRef]

32. Okafor, C.G.; Sadiku, O.E.S.; Okhimamhe, A.O.; Eichie, J. Households vulnerability and adaptation to climate variability induced water stress on downstream Kaduna river basin. Am. J. Clim. Chang. 2017, 6, 247-267. [CrossRef]

33. BBS (Bangladesh Bureau of Statistics). Community Report Satkhira Zila 2011; Ministry of Planning: Dhaka, Bangladesh, 2011.

34. The World Bank; BBS (Bangladesh Bureau of Statistics); The World Food Programme. Poverty Maps of Bangladesh 2010. 2010. Available online: http://203.112.218.65:8008/WebTestApplication/userfiles/Image/ LatestReports/Poverty_Map_brochure10.pdf (accessed on 28 July 2020). 
35. Kumar, U.; Baten, M.; Masud, A.; Osman, K.; Rahman, M. Cyclone Aila: One Year on, Natural Disaster to Human Suffering; Unnayan Onneshan: Dhaka, Bangladesh, 2010.

36. Braun, M.; Saroar, M. Participatory Action Research on Climate Risk Management, Bangladesh; Studies \& Reviews; World Fish: Penang, Malaysia, 2012; pp. 1-39.

37. Toufique, A.K.; Yunus, M. Vulnerability of Livelihoods in the Coastal Districts of Bangladesh; Development Studies, Bangladesh Institute of Development Studies (BIDS): Dhaka, Bangladesh, 2013; Volume 36, pp. 95-120.

38. NIPORT (National Institute of Population Research and Training); Mitra and Associates; Macro International. Bangladesh Demographic and Health Survey 2007; National Institute of Population Research and Training, Mitra and Associates, and Macro International: Dhaka, Bangladesh; Calverton, MD, USA, 2009.

39. Koirala, S. Livelihood Vulnerability Assessment to the Impacts of Socio-Environmental Stressors in Raksirang VDC of Makwanpur District Nepal. Master's Thesis, The Department of International Environment and Development Studies, Noragric, Norwegian University of Life Sciences, Trondheim, Norway, 2015.

40. Tewari, H.R.; Bhowmick, P.K. Livelihood vulnerability index analysis: An approach to study vulnerability in the context of Bihar. Jàmbá J. Disaster Risk Stud. 2014, 6, 1-13.

41. Huong, N.T.L.; Yao, S.; Fahad, S. Assessing household livelihood vulnerability to climate change: The case of Northwest Vietnam. Hum. Ecol. Risk Assess. 2018, 25, 1157-1175. [CrossRef]

42. Adu, D.T.; Kuwornu, J.K.M.; Anim-Somuah, H.; Sasaki, N. Application of livelihood vulnerability index in assessing smallholder maize farming households' vulnerability to climate change in Brong-Ahafo region of Ghana. Kasetsart J. Soc. Sci. 2018, 39, 22-32. [CrossRef]

43. Thorpe, W.; Erenstein, O.; Singh, J.; Varma, A. Crop-Livestock Interactions and Livelihoods in the Gangetic Plains of Bihar, India; International Livestock Research Institute: Nairobi, Kenya, 2007.

44. UNDP. Human Development Reports. 2007. Available online: http://hdr.undp.org/en/ (accessed on 22 March 2018).

45. Asmamaw, M.; Mereta, S.T.; Ambelu, A. Exploring households' resilience to climate change-induced shocks using Climate Resilience Index in Dinki watershed, central highlands of Ethiopia. PLoS ONE 2019, 14, e0219393. [CrossRef] [PubMed]

46. Sullivan, C. Calculating a Water Poverty Index. World Dev. 2002, 30, 1195-1210. [CrossRef]

47. BBS (Bangladesh Bureau of Statistics). Household Income and Expenditure Survey 2010; Ministry of Planning: Dhaka, Bangladesh, 2011.

48. Grist, N.; Seeley, J.; Maddox, B. Literature Review on Chronic and Extreme Poverty in Bangladesh; Livelihoods Monitoring Unit, Rural Livelihoods Program; CARE-Bangladesh: Dhaka, Bangladesh, 2006.

49. The World Bank Group. Piecing Together: The Poverty Puzzle; International Bank for Reconstruction and Development, The World Bank: Washington, DC, USA, 2018.

50. Siegel, P.B. Using an Asset-Based Approach to Identify Drivers of Sustainable Rural Growth and Poverty Reduction in Central America: Conceptual Framework; WPS 3475; The World Bank: Washington, DC, USA, 2005.

51. Rakodi, C. A livelihood approach-Conceptual issues and definitions. In Urban Livelihoods: A People-Centred Approach to Reducing Poverty; Rakodi, C., Lloyd-Jones, T., Eds.; Earthscan: London, UK, 2002.

52. Moser, C. The asset vulnerability framework: Reassessing urban poverty reduction strategies. World Dev. 1998, 26, 1-19. [CrossRef]

53. Moser, C. Asset-Based Approaches to Poverty Reduction in a Globalized Context: An Introduction to Asset Accumulation Policy and Summary of Workshop Findings; Brookings Institution: Washington, DC, USA, 2006.

54. Moser, C. Assets, and livelihoods: A framework for asset-based social policy. In Assets, Livelihoods and Social Policy; Moser, C., Dani, A.A., Eds.; The World Bank: Washington, DC, USA, 2008.

55. Moser, C. A conceptual and operational framework for pro-poor asset adaptation to urban climate change. In Cities and Climate Change; Hoornweg, D., Freire, M., Lee, J.M., Bhada-Tata, P., Yuen, B., Eds.; Urban Development Series; The World Bank: Washington, DC, USA, 2010.

56. UNDP; OPHI (Oxford Poverty \& Human Development Initiative). Global Multidimensional Poverty Index 2020: Charting Pathways out of Multidimensional Poverty: Achieving the SDGs; The United Nations Development Programme: New York, NY, USA; Oxford Poverty and Human Development Initiative: Oxford, UK, 2020.

57. Yusuf, A.A.; Francisco, H. Hotspots! Mapping Climate Change Vulnerability in Southeast Asia; Economy and Environment Program for Southeast Asia (EEPSEA): Singapore, 2010.

58. Do, T.; Nguyed, C.; Phung, T. Assessment of Natural Disasters in Vietnam's Northern Mountains; MPRA Paper No. 54209; Munich Personal RePEc Archive (MPRA): Munich, Germany, 2013. 
59. Choudhury, M.U.I.; Haque, C.E. "We are more scared of the power elites than the floods": Adaptive capacity and resilience of wetland community to flash flood disasters in Bangladesh. Int. J. Disaster Risk Reduct. 2016, 19, 145-158. [CrossRef]

60. Akter, S.; Mallick, B. The poverty-vulnerability-resilience nexus: Evidence from Bangladesh. Ecol. Econ. 2013, 96, 114-124. [CrossRef]

61. Usamah, M.; Handmer, J.; Mitchell, D.; Ahmed, I. Can the vulnerable be resilient? Co-existence of vulnerability and disaster resilience: Informal settlements in the Philippines. Int. J. Disaster Risk Reduct. 2014, 10, 178-189. [CrossRef]

62. Joakim, E.P.; Mortsch, L.; Oulahen, G. Using vulnerability and resilience concepts to advance climate change adaptation. Environ. Hazards 2015, 14, 137-155. [CrossRef]

63. Maru, Y.T.; Smith, M.S.; Sparrow, A.; Pinho, P.F.; Dube, O.P. A linked vulnerability and resilience framework for adaptation pathways in remote disadvantaged communities. Glob. Environ. Chang. 2014, 28, 337-350. [CrossRef]

(C) 2020 by the authors. Licensee MDPI, Basel, Switzerland. This article is an open access article distributed under the terms and conditions of the Creative Commons Attribution (CC BY) license (http://creativecommons.org/licenses/by/4.0/). 